\title{
Unilateral Vital Signs Monitoring Systems on IoT
}

\author{
Mr. Vinod Kumar Pa, Dr. U.B. Mahadevaswamy ${ }^{\mathrm{b}}$ \\ ${ }^{a}$ Assistant Professor, Department of EEE, ATME College of Engineering, Mysuru-570018, India. \\ ${ }^{b}$ Professor, Department of ECE, Sri Jayachamarajendra College of Engineering, Mysuru-08,India.
}

Received: 26 May 2017; Accepted: 11 September 2017; Published: 08 January 2018

\begin{abstract}
With the consistent development of remote sensor systems and Internet of Things (IoT) different parts of life will benefit. IoT based pervasive human services framework can possibly give blunder free restorative information and alarming system in basic conditions with constant checking. The device will minimize the need of devoted medicinal staff for patient checking and help the ailing to lead an ordinary life other than furnishing them with great restorative medical aid. This paper presents the working model which fuses sensors to gauge parameters like body temperature, blood pressure level \& pulse. A microcontroller board is utilized for examining the inputs from the patient. Additionally all the procedure parameters inside of an interim selectable by the patient are monitored. This is extremely valuable for future examination and survey of feeble wellbeing condition. For more flexible restorative applications, this venture can be extemporized, by consolidating continuous parameter observing parameters respiratory thoracic extension belt sensors and annunciation frameworks, in this manner making it valuable in clinics as an exceptionally effective and committed aid consideration unit.
\end{abstract}

Index Terms: Internet of Things, GSM- Global Standard Mobile Communication.

(C) 2018 Published by MECS Publisher. Selection and/or peer review under responsibility of the Research Association of Modern Education and Computer Science.

\section{Introduction}

Today's environment the healthcare plays a vital role in mankind. There have been numerous cases of health issues throughout the year. There needs to be continuously monitoring of the conditions even before the vital issues arise. So, it's pivotal to be connected to the healthcare.

\subsection{Introduction to IoT}

The Internet of Things (IoT) is the system of physical articles, gadgets, vehicles, structures and different 
things which are installed with hardware, programming, sensors, and system availability, which empowers these items to gather and fetch data [1][27]. The IoT permits items to be detected and controlled remotely crosswise over existing system infrastructure [2] making open doors for more straightforward joining between the physical world and PC based frameworks, and bringing about enhanced proficiency, exactness and financial benefit [3]. When IoT is increased with sensors and actuators, the innovation turns into an occasion of the more broad class of digital physical frameworks, which likewise envelops advances, for example, shrewd lattices, brilliant homes, keen transportation and savvy urban communities.

\subsection{Assessing IoT Prospects in Healthcare}

Worldwide Home Patient observing framework market has touched 85 billion in 2014 [5]. IoT is a troublesome advancement which connects interoperability difficulties to drastically change the route in which social insurance will be conveyed, driving better results, expanding proficiency and making medicinal services moderate[4]. Industry investigators anticipate that the capacity for patients to assume more liability of their wellbeing and the advancement of preventive measures are fit for upsetting current consideration conveyance and will shape the eventual fate of social insurance. The idea thought behind this task has been to think of an effective equipment stage and remote system engineering keeping in mind the end goal to remotely screen tolerant, for different restorative information including heart rate, circulatory strain, body temperature, measuring of oxygen focus in blood. The classifications of IoT based personalized healthcare systems are Clinical care and remote monitoring. [8][28][29].The applications can be characterized in light of the sort of system accessibility, scope, scale, heterogeneity, repeatability, client contribution and effect [6]. Today's medical devices were readily dependent on IoT for continuous real time data for analysis and it's been expanding and particular diminishing the expense of consideration [7]. IoT is the machine to machine (M2M) communication by linking physical and virtual objects through exploitation of data capture and communication capabilities [9]. All around, hypertension is a noteworthy ceaseless, non-transmittable ailment and a main source of death and incapacity in monetarily creating nations [11][12]. In the event that the arm is underneath heart level, the perusing will be too high, and on the off chance that it is above heart level, it will be too low [13].The arm ought to likewise be still and bolstered at the elbow, in light of the fact that moving the arm or broadening it without bolster implies applying the muscles [14]. The paper presents design and development of a Non-invasive wireless blood pressure data acquisition instrument for remote monitoring based Microcontroller and Bluetooth transmission kit [16]. Paper implements a cuff-less continuous blood pressure monitoring device, which is consisted of two acquisition modules and an Android smart-phone.[17]. [18] Presents a strategy where a man is at home, on a trek, or at his work place, he/she can stay associated with the specialist and he can make prompt move if fundamental. A wrist finger system design has come to existence to business sector [20]. [21] Presents a Reflectance-based heartbeat oximeter for noninvasively observing the oxygen immersion (SpO2) and heartbeat rate (PR). [22] Presents a low cost, microcontroller-based unit uses two light-discharging diodes as excitation sources, obtains reflectance information with a photodiode, and sends these crude photoplethysmography information to a PC by means of a RS-232 serial connection. [23] In this paper we exhibit the acknowledgment of a remote low power heart beat oximeter telemonitoring framework able to gauge and transmit patient's blood vessel blood-oxygen immersion (SpO2) level and heart rate (HR). [24] LM35 temperature sensor is utilized for estimation of body temperature and respiratory temperature [25] presents a paper on body temperature estimation utilizing remote checking framework. [26] Presents an outline utilizing a helpful remote temperature measuring gadget that is proposed fundamentally for expansive quantities of clients, not for individual use. By analysis the recent developments of vital signs monitoring, the problem were identified such as data error and accuracy in current measuring method and it needs to be updated. Design a heartbeat oximeter that gives clinicians a non intrusive sign of patient's cardiopulmonary status and to configuration body temperature estimation unit and to design pulse oximeter for accurate measurement of heart rate. Finally to build a GUI interface for monitoring the vital parameters is considered as big challenge. So the following section will give the details about the design and building a 
prototype of complex model which measures body temperature, blood pressure and heart rate in bits per second.

This paper has been divided into 6 sections, $1^{\text {st }}$ section gives introduction $\&$ literature review, $2^{\text {nd }}$ section updates about the latest monitoring system through IoT and system methodology, $3^{\text {rd }}$ section gives about system implementation and design methodology, section $4^{\text {th }}$ gives results and validation, section $5^{\text {th }}$ gives conclusion and section $6^{\text {th }}$ gives future enhancement.

\section{System Methodology}

The methodology of the proposed system consists of the following three major functionalities:

- Devising appropriate monitoring system for the measurement of vital parameters.

- Developing a proper data acquisition system to acquire the monitored data.

- To establish communication between the proposed system and the remote devices such as personal computers, mobile etc., using a suitable communication technology.

\subsection{Patient monitoring system}

A reliable transmission protocol for Wi-Fi based wireless patient monitoring is implement, a Wi-Fi device for fall monitoring which integrates detection, indoor positioning and other vital signs monitoring etc,. Design and implementation of real time embedded Tele-health Monitoring system is utilizing Team viewer software and low cost component to transmit data to physicians for monitoring, diagnosis and patients care at a significantly low cost, regardless of patient's location. The physiological parameters such as blood pressure, Pulse rate and Temperature are obtained, processed using PIC microcontroller and displayed on web page through html graphical user interface. If any vital parameter goes out of the normal range then alert SMS will be sent to Doctors or care taker. In microcontroller based Health care monitoring system using Sensor network, Blood pressure reading, heart rate or body temperature exceeds the standard range for any patient, the system is able to notify using alarming system. The whole system is controlled by microcontroller PIC18F64k22. Light signal is used in sensor network section of this embedded system as IR light does not have any harmful effect on human body when it works in continuous mode. Pulse rate calculation and body temperature determination is also embedded in this system using sensor network. The conventional method of measuring blood pressure employs volume oscillometric method and trained personal is required to measure the blood pressure and it's on continuously basic. Whereas the proposed method employs photoplethysmography technique and an illiterate patient can check his/her blood pressure just by pushing a button and measurement can be done on a continuous basis. The rate of change of blood volume in an organ such as wrist has a linear relationship with blood pressure. This rate of change of blood pressure in wrist is measured by an optical sensor network which estimates blood pressure.

The advantages of proposed system are low cost, stores and processes physiological data, provides communication through smart phones, personal computers, data is secured, reliable and system operates in real time. The system is designed to monitor patient under critical care more conveniently and accurately for diagnosing and can be interfaced with WIFI to bring it under network system and to facilities for the doctor to monitor the patient's condition sitting in his own office without being physically present near patient's bed.

\subsection{Data acquisition}

The main requirement of the proposed work is to transmit the acquired data to remote locations. Various communication technologies such as Wi-Fi, ZIGBEE, BLUETOOTH, GSM and GPRS are being used for data transmission. We have employed Wi-Fi technology that allows electronic devices to connect to a wireless LAN (WLAN) network and based on IEEE 802.11 standards. Such access point has range of 20 metres indoor and 
greater outdoor ranges. GSM standard is used for mobile communication. SMS facilities is also provided as a part of GSM communication.

\section{System Implementation}

We have developed separate units to measure body temperature, blood pressure and heart rate. All the three units are integrated on same board and are controlled by the microcontroller during the measurement and transmission of vital parameters.

\subsection{Measurement of body Temperature}

For the measurement of body temperature, we have employed DS18S20 sensor which gives the output in digital format which is an indicative of temperature to be measured in degree centigrade. The sensor has an inbuilt IC which produces 3 states namely high, low and tri-state. A high state implies that temperature is increased over previous value, low state indicates decrease in temperature with respect to the previous value and the tri-state means that there is no change in temperature. The sensor is capable of measuring temperature over a wide range from $-55^{\circ} \mathrm{C}$ to $+125^{\circ} \mathrm{C}$. Since it gives output in digital format the microcontroller can directly read the sensor output and no conversion is required.

\subsection{Measurement of Heart Rate}

Transmittance and reflectance are two methods used for measuring heart rate. In transmittance technique, light from the source needs be to transmitted through the tissues. But this is troublesome in case of disjoint in finger bone, since light cannot pass through it. Hence we have adopted reflectance technique which is illustrated in Fig. 1. In this technique, light source strikes blood tissue and returns back. Heart rate is estimated from the return light signal.

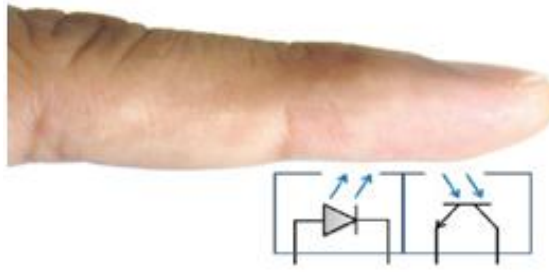

Fig.1. Finger Photoplethysmography (Reflectance Approach)

When forefinger is placed on sensor \& the enable input is made high, the sensor produces Infra red light at $940 \mathrm{~nm}$ as shown in block diagram of Fig.2. This light hits blood tissue \& gets reflected which is sensored by photo transistor of the sensor. The sensor output consists of series of pulse whose frequency depends on heart rate. These pulses are subjected to signal conditioning in which following processes are done:

- Filtering of the signals to eliminate unwanted elements.

- Amplification to boost the signal to required level.

- Convertion of signal into TTL waveform.

The TTL converted signals is applied to microcontroller which counts pulses for a duration of 15 seconds. This counts is multipled by 4 to get heart rate per minute $\&$ it is displayed on LCD and made available on user webpage also. 


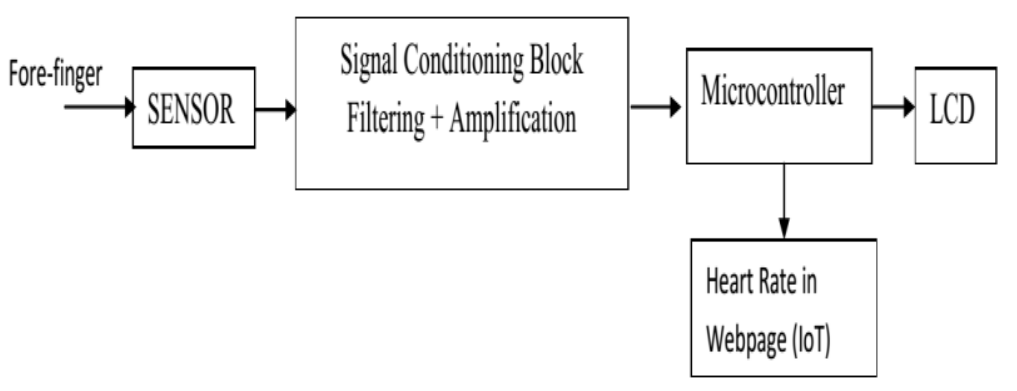

Fig.2. Block Diagram of Pulse Oximeter

\subsection{Blood Pressure}

The block diagram of proposed system for measurement of blood pressure is shown in Fig. 3. The system comprises of microcontroller, pressure transducer, cuff, motor and signal conditioning and ADC circuit for conversions.

When the user presses the button, microcontroller sends a control signal which turns on the motor. The motor pumps air into cuff. The pressure transducer generates two output signals with a time gap of $20 \mathrm{~ms}$. The first output signal corresponds to systolic pressure and second one corresponds to diastolic pressure. These two voltage levels are converted to their digital equivalents and then fed to the microcontroller. The microcontroller compares these values with those stored lookup table, fetch the matched systolic and diastolic pressures and displays on LCD. The same information is also made available on user web page.

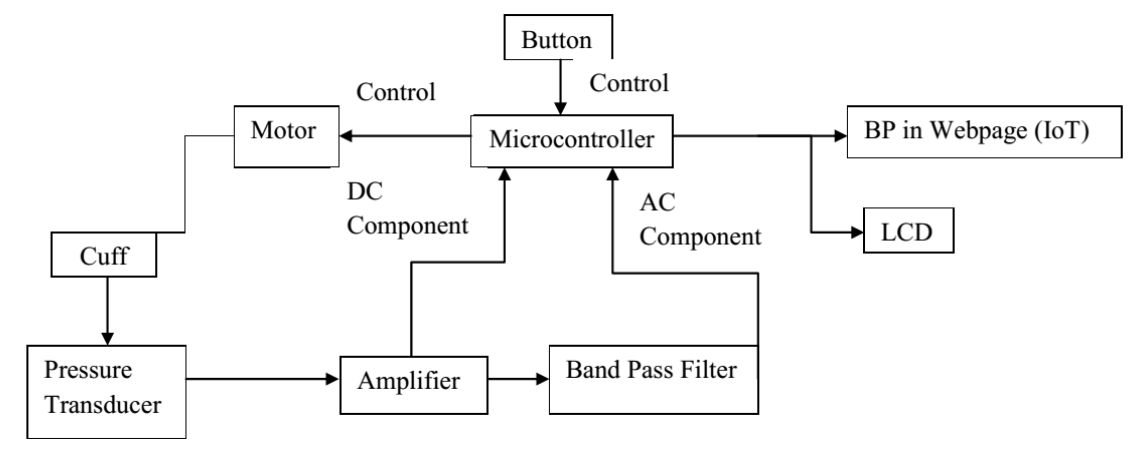

Fig.3. Schematic Block Diagram of BP unit.

\section{Results and Validation}

The proposed system is capable of recognizing the changes in vital parameters and takes about less than a millisecond to detect the abnormalities in these parameters. The memory requirement is also less. The proposed system allows multiple users to access the patient information as shown in Fig. 4. The snapshot of measurement of vital signs of a patient using proposed system is shown in Fig. 5. 


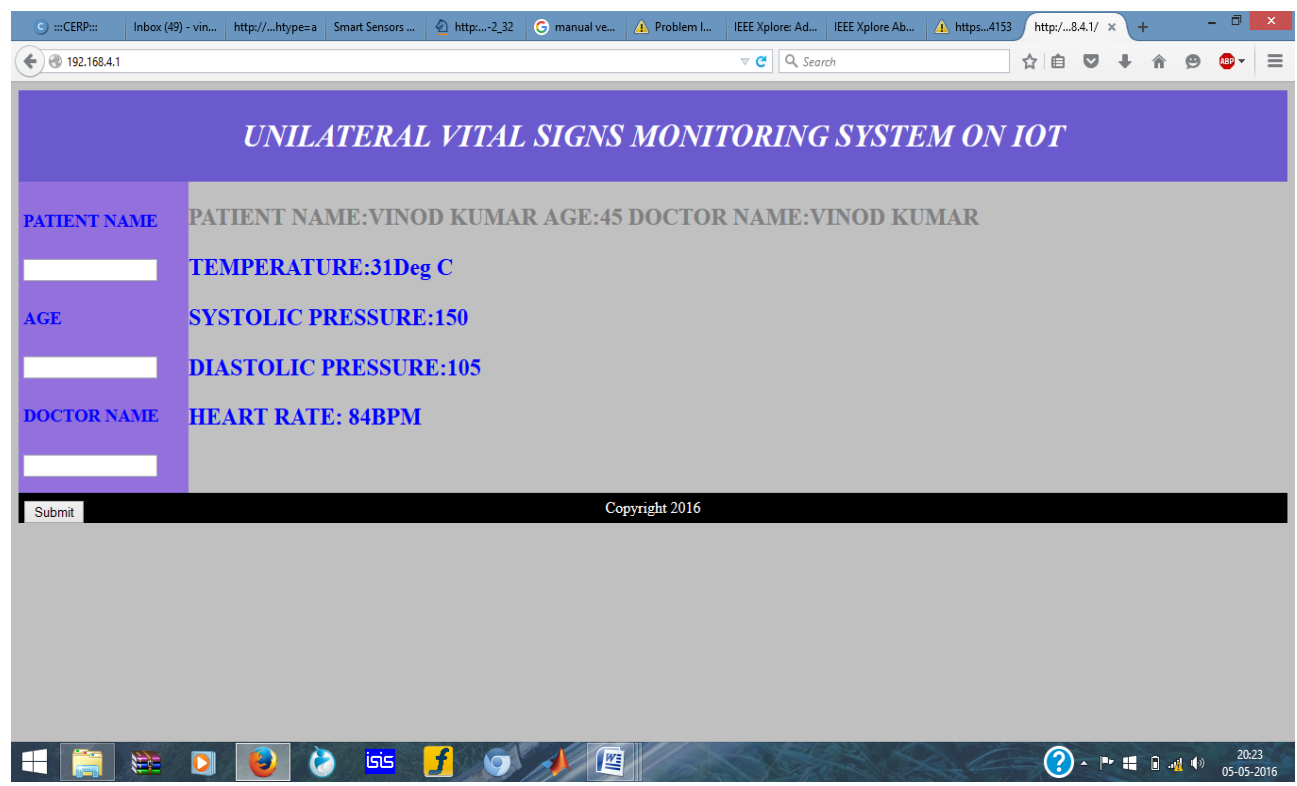

Fig.4. Screenshot of the Real Time Results on Webpage

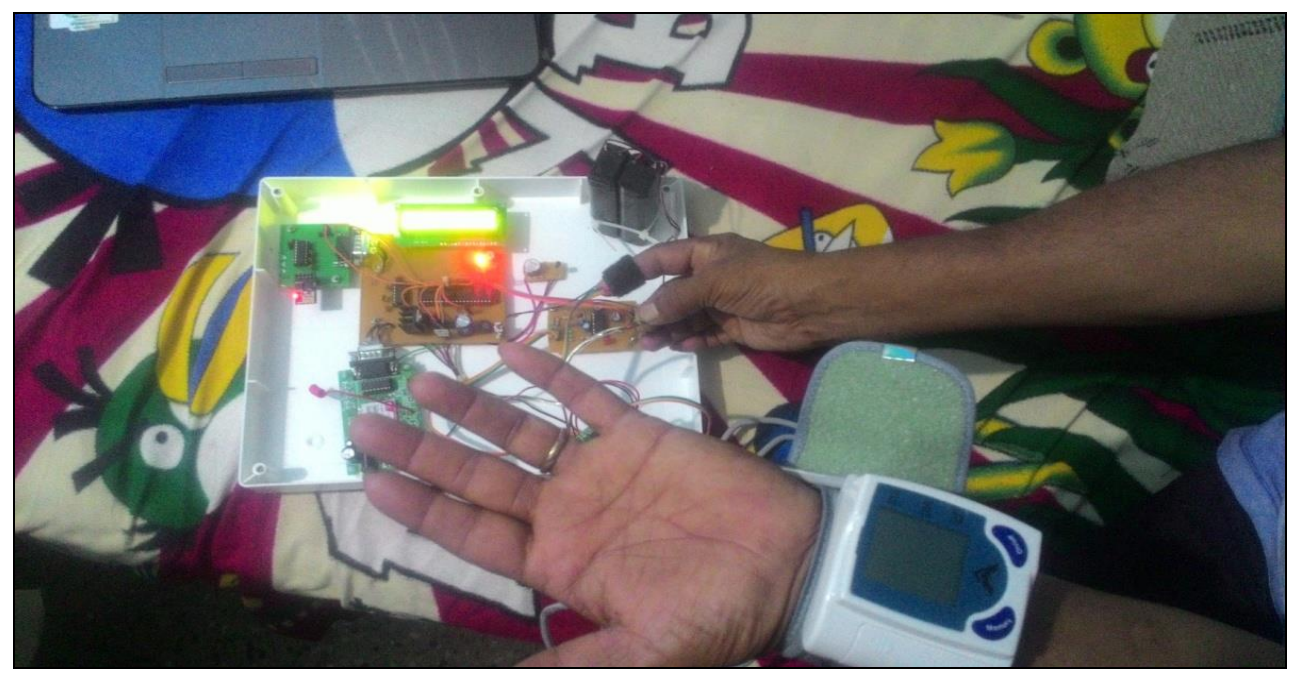

Fig.5. Snapshot of a Patient Being Tested by Proposed Model.

Measurement of heart rate, blood pressure and body temperature was carried out on 10 patients of varying age group ( 23 to 62 years) using the proposed model and measurement was also done on the same set of patients by an authorized physician. The results are compared in tables 1,2 and 3 . 
Table 1. Comparison of Heart Rate Measured by the Proposed System with That Recorded By Physician.

\begin{tabular}{|c|c|c|c|c|c|}
\hline \multirow{2}{*}{ SL. No. } & \multirow{2}{*}{$\begin{array}{l}\text { Patient } \\
\text { name }\end{array}$} & \multirow{2}{*}{ Age } & \multicolumn{2}{|l|}{ Heart rate (bpm) } & \multirow{2}{*}{ *Error(\%) } \\
\hline & & & $\begin{array}{l}\text { As recorded by } \\
\text { Physician }\left(\mathrm{HR}_{1}\right)\end{array}$ & $\begin{array}{l}\text { Measured by proposed } \\
\text { model }\left(\mathrm{HR}_{2}\right)\end{array}$ & \\
\hline 1 & XXXXX1 & 23 & 91 & 89 & +2.1 \\
\hline 2 & XXXXX2 & 37 & 97 & 96 & +1.0 \\
\hline 3 & XXXXX3 & 42 & 89 & 91 & -2.2 \\
\hline 4 & XXXXX4 & 54 & 100 & 100 & 0.0 \\
\hline 5 & XXXXX5 & 58 & 85 & 84 & +1.1 \\
\hline 6 & XXXXX6 & 27 & 87 & 87 & -1.1 \\
\hline 7 & XXXXX7 & 35 & 86 & 83 & +3.4 \\
\hline 8 & XXXXX8 & 43 & 90 & 89 & +1.1 \\
\hline 9 & XXXXX9 & 56 & 101 & 100 & +1.1 \\
\hline 10 & XXXXX10 & 62 & 91 & 93 & -2.2 \\
\hline
\end{tabular}

*\% Error $=\left(\mathrm{HR}_{1}-\mathrm{HR}_{2}\right) / \mathrm{HR}_{1} * 100$

Observe from table 1 that, the error in heart rate measurement lies in the range from $-2.2 \%$ to $+3.4 \%$. This error is tolerable. The error is due to influence of ambient light.

Table 2. Comparison of body temperature measured by proposed system with that recorded by physician.

\begin{tabular}{|l|l|c|c|c|c|}
\hline \multirow{2}{*}{$\begin{array}{l}\text { SL. } \\
\text { No. }\end{array}$} & \multirow{2}{*}{ Patient name } & Age & \multicolumn{2}{|c|}{ Body temperature (ac) } & \multirow{2}{*}{ *Error (\%) } \\
\cline { 3 - 5 } & & & $\begin{array}{c}\text { As recorded by } \\
\text { Physician }\left(\mathrm{T}_{1}\right)\end{array}$ & $\begin{array}{c}\text { Measured by } \\
\text { proposed model }\left(\mathrm{T}_{2}\right)\end{array}$ & $\mathbf{+ 1 . 6}$ \\
\hline 1 & XXXXX1 & 23 & 30.5 & 28 & $\mathbf{+ 1 . 0}$ \\
\hline 2 & XXXXX2 & 37 & 28.3 & 32 & $\mathbf{+ 1 . 2}$ \\
\hline 3 & XXXXX3 & 42 & 32.4 & 31 & $\mathbf{- 0 . 6}$ \\
\hline 4 & XXXXX4 & 54 & 30.8 & 30 & $\mathbf{+ 2 . 2}$ \\
\hline 5 & XXXXX5 & 58 & 30.7 & 29 & $\mathbf{- 0 . 3}$ \\
\hline 6 & XXXXX6 & 27 & 28.9 & 29 & $\mathbf{+ 0 . 3}$ \\
\hline 7 & XXXXX7 & 35 & 29.1 & 30 & $\mathbf{0 . 0}$ \\
\hline 8 & XXXXX8 & 43 & 30 & 31 & $\mathbf{- 0 . 3}$ \\
\hline 9 & XXXXX9 & 56 & 30.9 & 32 & $\mathbf{0 . 3}$ \\
\hline 10 & XXXXX10 & 62 & 32.1 & & \\
\hline
\end{tabular}

The error introduced in temperature measurement varies from $-0.6 \%$ to $+2.2 \%$, as given in table 2 . This amount of error is also within the tolerable limit. The error is due to fact that the proposed system displays the temperature in whole number whereas reading record by physician as decimal places. 
Table 3. Comparison of Blood Pressure Measured by Proposed System with That Recorded by Physician

\begin{tabular}{|c|c|c|c|c|c|c|}
\hline \multirow{2}{*}{$\begin{array}{l}\text { SL } \\
\text { No. }\end{array}$} & \multirow[t]{2}{*}{ Patient Name } & \multirow[t]{2}{*}{ Age } & \multicolumn{2}{|c|}{ Blood Pressure (mmHg) } & \multirow[b]{2}{*}{ *Error-1(\%) } & \multirow[b]{2}{*}{$*$ Error-2(\%) } \\
\hline & & & $\begin{array}{l}\text { As recorded by } \\
\text { Physician }\left(\mathrm{BP}_{1}\right) \\
(\text { Systolic- }(\mathrm{S} 1) / \\
\text { Diastolic -(D1)) }\end{array}$ & $\begin{array}{l}\text { Measured by } \\
\text { proposed model } \\
\left(\mathrm{BP}_{2}\right)(\text { Systolic- } \\
(\mathrm{S} 2) / \text { Diastolic- } \\
(\mathrm{D} 2))\end{array}$ & & \\
\hline 1 & $\mathrm{XXXXX1}$ & 23 & $120 / 83$ & $123 / 84$ & -2.5 & -1.1 \\
\hline 2 & $\mathrm{XXXXX2}$ & 37 & $130 / 90$ & $130 / 93$ & 0.0 & -3.3 \\
\hline 3 & XXXXX3 & 42 & $140 / 100$ & $140 / 101$ & 0.0 & -1 \\
\hline 4 & $\mathrm{XXXXX4}$ & 54 & $120 / 90$ & $120 / 89$ & 0.0 & 1.1 \\
\hline 5 & XXXXX5 & 58 & $155 / 106$ & $150 / 105$ & 3.2 & 0.9 \\
\hline 6 & XXXXX6 & 27 & $130 / 100$ & $127 / 97$ & +2.3 & +3.0 \\
\hline 7 & XXXXX7 & 35 & $120 / 95$ & $118 / 92$ & +1.6 & +3.1 \\
\hline 8 & XXXXX8 & 43 & $125 / 85$ & $124 / 85$ & +0.8 & +3.4 \\
\hline 9 & XXXXX9 & 56 & $140 / 100$ & $138 / 97$ & +1.4 & +3.0 \\
\hline 10 & XXXXX10 & 62 & $130 / 90$ & $129 / 89$ & +0.76 & +1.1 \\
\hline
\end{tabular}

$* \%$ Error-1 $=\left(\mathrm{S}_{1}-\mathrm{S}_{2}\right) / \mathrm{S}_{1} * 100 * \%$ Error-2 $=\left(\mathrm{D}_{1}-\mathrm{D}_{2}\right) / \mathrm{D}_{1} * 100$

Observe from table 3 that the error introduced in the measurement of blood pressure is $\pm 3.4 \%$ which is in the acceptable limits.

\section{Conclusion}

We have developed a system which measures human vital parameters such as body temperature, blood pressure and heart rate. The proposed system is cost effective, reliable and easy to use. Measurement on ten different patients with varying age group was done using proposed model. The results were tabulated and compared with the readings of same ten patients recorded by the physician.

On accuracy point of view, proposed model gives an error of maximum $\pm 3 \%$. The error introduced is accounted as follows:

- The light from surrounding source will have an influence on measurement of heart rate.

- The accuracy of the digital output from the sensor decides the error in case of temperature measurement.

- The proposed system gives reading of blood pressure in digital which has fractional part whereas the readings obtained from the conventional method are whole numbers. The time gap between systolic and diastolic pressures should be correctly estimated.

\section{Future Enhancement}

Since the proposed system is WIFI based and does not use the server, the measured data of a patient can be accessed by an authorized person at a distance of 20 metre only. As a future enhancement a server can be used in which the measured data can be updated so that information regarding patient can be accessed and analyzed from far off place by a specialist.

The proposed system can be expanded to measure some more vital parameters such as SPO2, ECG and blood glucose level (non-invasive) with data available on server. 


\section{References}

[1] "Internet of Things Global Standards Initiative". ITU. Retrieved 26 June 2015.

[2] https://hbr.org/resources/pdfs/comm/verizon/18980_HBR_Verizon_IoT_Nov_14.pdf.

[3] http://www.internet-of-things research.eu/pdf/Converging Technologies for Smart Environments and Integrated Ecosystems IERC Book Open Access 2013.pdf.

[4] Dave Evans (April 2011). "The Internet of Things: How the Next Evolution of the Internet Is Changing Everything" (PDF). Cisco. Retrieved 4 September 2015.

[5] Gartner, IT Glossary, Internet of Things - http://www.gartner.com/it-glossary/internet-of-things/.

[6] A. Gluhak, S. Krco, M. Nati, D. Pfisterer, N. Mitton, T. Razafindralambo, A survey on facilities for experimental Internet of Things research, IEEE Communications Magazine 49 (2011) 58-67.

[7] David Niewolny. 18 Oct 2013. How the Internet of Things Is Revolutionizing Healthcare, Freescale Semiconductors.

[8] Mikhail Simonov, Riccardo Zich, Flavia Mazzitelli. Personalised healthcare communication in Internet of Things.

[9] Jara, A. J., Zamora, M. A., Skarmeta, A. F. \& G. 2011. An internet of things-based personal device for diabetes therapy management in ambient assisted living (AAL). Personal and Ubiquitous Computing, 15(4), 431-440.

[10] Murray C, Lopez A. Mortality by cause for eight regions of the world: Global Burden of Disease Study. The Lancet, 1997. 349(9061): p. 1269-1276.

[11] Goldman L, Ausiello D. Cecil Medicine. Saunders Elsevier Philadelphia, PA, 2008.

[12] Daar A, Singer P, Persad D, Pramming S, Matthews D, Beaglehole R, Bernstein A, Borysiewicz L, Colagiuri S, Ganguly N, Glass R, Finegood D, Koplan J, Elizabeth G, Nabel E, Sarna G, Sarrafzadegan N, Smith R, Yach D, Bell J. Grand challenges in chronic non-communicable diseases. Nature, 2007. 450(7169): p. 494-496.

[13] Beevers, Gareth, Gregory Y H Lip, and Eoin O’Brien. "Blood Pressure Measurement." British Medical Journal 322(7292) (2001): pp.: 981 - 985.

[14] Jiri Jilek. Electronic Sphygmomanometers: The Problems and Some Suggestions. Biomedical Instrumentation \& Technology: July 2003, Vol. 37, No. 4, pp. 231-233.

[15] Chris Riha. Protecting and Securing Networked Medical Devices. Biomedical Instrumentation \& Technology: September 2004, Vol. 38, No. 5, pp. 392-396.

[16] B. A. Zneid, M. Al-zidi; T. Al-kharazi "Non-invasive blood pressure remote monitoring instrument based microcontroller", IEEE Region 10 Symposium,14-16 April,2014.

[17] Shivaraman Ilango1, Pooja Sridhar2, "A Non-Invasive Blood Pressure Measurement using Android Smart Phones", IOSR Journal of Dental and Medical Sciences (IOSR-JDMS) e-ISSN: 2279-0853, pISSN: 2279-0861. Volume 13, Issue 1 Ver. IV (Jan. 2014), pp.: 28-31.

[18] 1D.Chandana, 2B.Hema Latha, "A Tele-medicine System for Measuring Heart Rate, Blood pressure, And Drug Level Detection", IJEDR | Volume 2, Issue 1 | ISSN: 2321-9939, 2014.

[19] Townsend, Neil. "Pulse Oximetry." Medical Electronics, Michaelmas Term 2001. <http://www.robots.ox.ac.uk/ neil/teaching/lectures/med_elec/notes6.pdf>.

[20] Robert Croce and Jenna M. Sullivan, “Accessible Home Vital Signs Monitoring System” Rehabilitation Engineering Research Center on Accessible Medical Instrumentation.

[21] G. Di, X. Tang, and W. Liu, "A reflectance pulse oximeter design using the MSP430F149," in Proc. IEEE/ICME Int. Conf. Complex Med. Eng., May 2007, pp. 1081-1084.

[22] Alexandra Fontaine, Arben Koshi, Danielle Morabito, Nicolas Rodriguez, "Reflectance based Pulse Oximeter for the chest and wrist" thesis report, WORCESTER POLYTECHNIC INSTITUTE.

[23] Jianchu Yao, M.S. and Steve Warren, "Stimulating Student Learning with a Novel "In-House" Pulse 
Oximeter Design", Department of Electrical \& Computer Engineering, Kansas State University Manhattan, KS 66506, USA.

[24] F. Adochiei C. Rotariu ; R. Ciobotariu; H. Costin, "A wireless low-power pulse oximetry system for patient telemonitoring", 7th International Symposium on Advanced Topics in Electrical Engineering (ATEE), 12-14 May 2011.

[25] Body temperature measurement using PIC 16f877a microcontroller http://kitsnspares.com/admin/pdffiles/temp.pdf.

[26] H. Mansor, M. H. A. Shukor; S. S. Meskam; N. Q. A. M. Rusli ; N. S. Zamery. "Body temperature measurement for remote health monitoring system", IEEE International Conference on Smart Instrumentation, Measurement and Applications (ICSIMA), 25-27 Nov. 2013.

[27] Suresh Sankaranarayanan, Au Thien Wan, Aida Harayani Pusa,"Smart Home Monitoring using Android and Wireless Sensors", IJEM, vol.4, no.2, pp.12-30, 2014.

[28] Kadhim M.Hashem, Fatima Ghali,"Human Identification Using Foot Features", International Journal of Engineering and Manufacturing(IJEM), Vol.6, No.4, pp.22-31, 2016.

[29] Haleema Inam, Asma Malik, Marina Hayat, Aliya Ashraf, "A Survey on Facial Expression Recongnition Technology and Its Use in Virtual System", International Journal of Engineering and Manufacturing(IJEM), Vol.4, No.2, pp.11-18, 2015.

\section{Authors' Profiles}

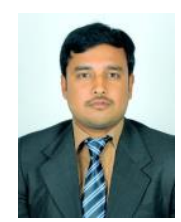

Mr. Vinod Kumar P has completed his BE degree in Electrical \& Electronics in the year 2010 from Visvesvaraya Technological University, M.Tech in VLSI \& Embedded Systems from Visvesvaraya Technological University in the year of 2016. He is presently working as Assistant Professor in the department of Electrical \& Electronics Engineering of ATME College of Engineering, Mysuru, Karnataka, India. He has published technical and research papers in international journals and conferences. His research interest includes the topics; Medical electronics \& embedded systems

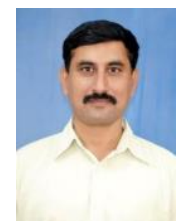

Dr. U. B. Mahadevaswamy has completed his BE degree in Electronics and Communication in the year 1988 from University of Mysore, M.Tech in industrial electronics in the year 1995 from Mangalore University and obtained $\mathrm{PhD}$ in electronics from University of Mysore in the year 2013. He is presently working as Associate professor in the department of electronics and communication of Sri Jayachamarajendra College of Engineering, Mysuru, Karnataka, India. He has authored several textbooks and published many technical and research papers in international journals and conferences. His research interest includes the topics; wireless sensors networks, VLSI design, embedded systems and digital signal processing.

How to cite this paper: Vinod Kumar P, U.B. Mahadevaswamy,"Unilateral Vital Signs Monitoring Systems on IoT", International Journal of Engineering and Manufacturing(IJEM), Vol.8, No.1, pp.53-62, 2018.DOI: 10.5815/ijem.2018.01.05 